\title{
Time-course of leptin levels in term and preterm human milk
}

\author{
J Bielicki, R Huch and U von Mandach \\ Department of Obstetrics, Zurich University Hospital, Frauenklinikstrasse 10, CH-8091 Zurich, Switzerland \\ (Correspondence should be addressed to U von Mandach; Email: ursula.vonmandach@usz.ch)
}

\begin{abstract}
Objective: To compare the time-course of breast milk leptin levels between term and preterm pregnancy.

Design: Open longitudinal prospective randomised study.

Methods: RIA of leptin levels in milk from 33 mothers (term pregnancy: $n=24$; preterm: $n=9$ ) at three postpartum intervals: 2-3 days, 4-5 days and 6 weeks (intervals A, B and C), combined with serum in 23 mothers (term: $n=17$; preterm: $n=6$ ) in interval A. Milk samples were sonicated before incubation.

Results: Interval A leptin levels were approximately tenfold higher in serum than in milk (term: $13.24 \pm 2.48$ vs $1.34 \pm 0.14 \mathrm{ng} / \mathrm{ml}, P<0.0001$; preterm: $4.46 \pm 1.05$ vs $0.63 \pm 0.18 \mathrm{ng} / \mathrm{ml}$, $P<0.0005)$, and higher in term than in preterm serum $(P=0.03)$. Milk levels were higher in the term vs preterm group in intervals $\mathrm{A}(P<0.01)$ and $\mathrm{B}(P<0.05)$. In the term group they declined significantly from interval A to interval B $(P<0.05)$ but did not vary significantly in the preterm group. Serum levels correlated with maternal body mass index; milk levels showed only moderate correlation with maternal and infant weight or body mass index.

Conclusion: The reasons for the presence and differential longitudinal expression of leptin in human milk after term and preterm pregnancy remain unknown. A hypothesis, requiring further study, is that persistently lower leptin levels in preterm milk act as a compensatory release of a brake on neonatal growth.
\end{abstract}

European Journal of Endocrinology $151271-276$

\section{Introduction}

Leptin, the 167 amino acid polypeptide hormone product of the $o b$ gene (1), is involved in the regulation of metabolism and body weight. Over the last decade, it has been intensively investigated in the prototypical growth state of pregnancy (2), with the evidence indicating a maternofetal supportive role beginning in early gestation (3) and persisting through lactation (4).

Studies of leptin expression in human milk have shown a general correlation with maternal plasma levels (5-7), maternal body mass index (BMI) as a measure of adiposity $(6,8,9)$ and infant plasma levels (7). In normal term milk, the concentrations of growth factors and other growth-promoting substances are high in colostrum, then decline to a plateau (10). Preterm breast milk displays compensatory changes in fat composition and growth factors (11), prolonging the colostrum-like period and greatly delaying the transition to the mature milk plateau (12). The shorter the gestation, the greater would appear to be the growthpromoting activity of preterm milk.

To determine whether this pattern also applies to leptin, we undertook a longitudinal and comparative study of human milk leptin expression after term and preterm pregnancy. Only one previous study, that by Resto et al. (13), has to our knowledge measured leptin in preterm human milk. It found highly variable levels similar to those reported for term breast milk, but it was not longitudinal, nor did not incorporate its own term controls.

\section{Materials and methods}

\section{Subjects and study design}

Following local ethical committee approval, lactating women in the obstetric unit of Zurich University Hospital, Switzerland were recruited with their informed consent over a 3-month period into an open prospective randomised longitudinal study. Inclusion criteria were term deliveries after uncomplicated pregnancies and preterm deliveries, defined as $<37.0$ weeks of gestation by ultrasound. Non-inclusion criteria were multiple gestation, delivery within the previous 2 years, pre-existing maternal disease, fetal malformation, preeclampsia, BMI $>35.0$ at inclusion $(2-3$ days postpartum) and lactation failure.

Milk sample collection was standardised by milk volume and time: $5.0 \mathrm{ml}$ were collected in graduated 
plastic tubes using an electric pump (Medela International, Baar, Switzerland; www.medela.ch) $1-3 \mathrm{~h}$ after a continental breakfeast (bread, butter, marmalade and coffee or tea) and just before suckling. Samples were immediately stored at $4^{\circ} \mathrm{C}$, then vortexed later the same day before being pipetted into $800 \mu \mathrm{l}$ aliquots (1.0 ml Eppendorf tubes) and finally stored at $-20{ }^{\circ} \mathrm{C}$. Collection was performed in all women at two intervals postpartum: 2-3 days (A) and 4-5 days (B). A third interval, 4-6 weeks postpartum (C) was considered for women who had not left the country $(95 \%$ of patients in the hospital are foreigners). If routine postpartum monitoring was performed, maternal blood $(5 \mathrm{ml})$ was collected at the same time as the first milk sample, refrigerated immediately after venepuncture, then centrifuged and the serum transferred into $800 \mu \mathrm{l}$ aliquots for storage at $-20^{\circ} \mathrm{C}$ until analysis.

Maternal body weight was determined using digital scales (increment: 100 g; Soehnle, Murrhardt, Germany; www.soehnle.de) at intervals $\mathrm{A}$ and $\mathrm{C}$, and the mean of consecutive triplicate measures computed with height to derive the BMI (weight $(\mathrm{kg}) /$ height $\left.(\mathrm{m})^{2}\right)$. All other data were obtained from the patients' notes.

\section{Leptin RIA}

We used a human leptin polyclonal antibody RIA (human-leptin-sensitive RIA; Mediagnost, Reutlingen, Germany; www.mediagnost.de) designed for measurement in serum and plasma, but also recommended for other biological fluids. Intra-assay variation was $<5 \%(<10 \%$ for milk samples $<1 \mathrm{ng} / \mathrm{ml})$ and interassay variation was $<7.6 \%$ (5.4\% for serum samples, $9.7 \%$ for milk samples; two samples with different concentrations analysed on 5 different days) with a detection limit of $0.25 \mathrm{ng} / \mathrm{ml}$ using $100 \mu \mathrm{l}$ samples. All milk and serum samples from the same subject were assayed in duplicate in the same test battery. After dilution according to the maternal BMI to ensure that leptin levels were in the range measurable by the RIA, the serum samples were assayed without difficulty using the manufacturer's protocol.

Given evidence that leptin levels are higher in whole than in skim milk and that the type of homogenisation procedure results in slightly different levels $(6,8)$, we analysed whole milk samples twice, once after a single $10 \mathrm{~s}$ burst of sonication and once after conventional vortexing before incubation. The optimal time of sonication was tested before $(<$ and $>10$ s/burst, one, two and three bursts; no higher leptin levels were obtained with $>1$ burst and/or $>10 \mathrm{~s}$ ). Milk samples were spiked with two different concentrations of human leptin and the recovery was determined.

\section{Statistics}

Statistical analysis was performed using SPSS 10 and StatView 4.51 (Abacus Concept, Berkeley, CA, USA) for Windows. The Kolmogorov-Smirnov test was used for normality, and the Wilcoxon signed rank test as well as the paired $t$-test of log values to detect longitudinal patterns. Term vs preterm differences were examined using the Mann-Whitney $U$ test as well as the unpaired two-tailed $t$-tests of log values. Bonferroni correction was used for the non-parametric tests. Group interaction with other parameters was tested using ANOVA. Correlations between two variables were tested by multiple and simple regression. A $P$ value $<0.05$ was considered significant in all tests.

\section{Results}

\section{Subjects}

After the exclusion of one woman because of unclear gestational age at delivery, the population $(n=33)$ numbered 24 women in the term group and nine in the preterm group. The causes of preterm delivery were preterm premature rupture of the membranes $(n=5)$, placental detachment $(n=2)$ and placenta previa $(n=2)$. Four of these nine women received single-dose fetal lung maturation induction with intravenous betamethasone, 8 days prepartum $(n=3)$ and 21 days prepartum $(n=1)$. The groups did not differ significantly in parity, mode of delivery, infant sex, or maternal age, weight or BMI (Table 1).

\section{Analytical procedure}

In serum, preincubation vortexing yielded slightly higher levels than sonication. In milk, sonication yielded significantly higher values than vortexing in intervals A $(1.15 \pm 0.12(1.04))$ vs $0.90 \pm 0.11(0.58)$ $\mathrm{ng} / \mathrm{ml} ; \quad P<0.0001)$ and $B(0.79 \pm 0.10(0.56)$ vs $0.66 \pm 0.10(0.46) \mathrm{ng} / \mathrm{ml} ; P<0.005)$. The difference in interval $C$ was non-significant. Over $90 \%$ of values after the sonication procedure were positive $(P<0.0001$ vs vortexing). Values $<0.25 \mathrm{ng} / \mathrm{ml}$ were entered as $0.24 \mathrm{ng} / \mathrm{ml}$ in the $\log$ statistical analyses (no zero values). Milk samples spiked with 1 and $5 \mathrm{ng} / \mathrm{ml}$ human leptin were parallel to the standard curve of samples in assay buffer or serum (identically treated with sonication procedure before incubation). The recovery of spiked milk samples was $97 \%$ in the test series (Table 2). For statistical evaluation, only values from the sonication procedure were used.

\section{Serum and milk leptin, term vs preterm delivery, longitudinal pattern}

Serum samples were available from 23 women (term: $n=17$; preterm: $n=6$; not performed routine venepuncture accounted for the ten missing samples). Milk collections in intervals A and B were complete; in interval C, samples were obtained from 28 women 
Table 1 Data of mothers and their infants (means \pm S.E. (median)).

\begin{tabular}{|c|c|c|}
\hline & Term delivery $(n=24)$ & Preterm delivery $(n=9)$ \\
\hline \multicolumn{3}{|l|}{ Mother } \\
\hline Age (years) & $28.4 \pm 1.1(28.0)$ & $30.4 \pm 2.0(29.0)$ \\
\hline Parity & $1.6 \pm 0.1(1.0)$ & $1.3 \pm 0.2(1.0)$ \\
\hline Height (m) & $1.64 \pm 0.02(1.64)$ & $1.68 \pm 0.02(1.69)$ \\
\hline \multicolumn{3}{|l|}{ Interval A } \\
\hline Weight (kg) & $69.1 \pm 2.3(69.7)$ & $66.6 \pm 3.1(67.6)$ \\
\hline $\mathrm{BMI}\left(\mathrm{kg} / \mathrm{m}^{2}\right)$ & $25.66 \pm 0.77(25.09)$ & $23.76 \pm 1.16(22.85)$ \\
\hline \multicolumn{3}{|l|}{ Interval C } \\
\hline Weight (kg) & $66.09 \pm 2.56(64.7)^{1}$ & $61.31 \pm 3.12(62.4)^{2}$ \\
\hline $\mathrm{BMI}\left(\mathrm{kg} / \mathrm{m}^{2}\right)$ & $24.42 \pm 0.85(23.75)^{1}$ & $21.75 \pm 0.84(21.09)^{2}$ \\
\hline Vaginal delivery or non-elective CS $(n)$ & 21 & 8 \\
\hline Elective CS $(n)$ & 3 & 1 \\
\hline \multicolumn{3}{|l|}{ Infant } \\
\hline Gestational age at birth (weeks) & $39.42 \pm 0.22(39.43)$ & $32.11 \pm 1.16(33.57)^{\star}$ \\
\hline Weight at birth (kg) & $3.238 \pm 0.10$ (3.315) & $1.912 \pm 0.25(2.230)^{\star \star}$ \\
\hline Weight at birth (percentile) & $44.7 \pm 6.0(45.5)$ & $47.1 \pm 7.0(41.5)$ \\
\hline Length at birth $(\mathrm{m})$ & $0.49 \pm 0.01(0.50)$ & $0.42 \pm 0.02(0.43)$ \\
\hline BMI at birth $\left(\mathrm{kg} / \mathrm{m}^{2}\right)$ & $13.35 \pm 0.26(13.41)$ & $10.61 \pm 0.74(11.06)^{\star \star \star}$ \\
\hline $\operatorname{Sex}(\mathrm{M} / \mathrm{F}(n))$ & $10 / 14$ & $5 / 4$ \\
\hline
\end{tabular}

${ }^{1} n=21 ;{ }^{2} n=7$; A: $2-3$ days postpartum; C: $4-6$ weeks postpartum; CS: Caesarean section; M: male; F: female.

${ }^{\star} P<0.0001,{ }^{\star \star} P<0.0005,{ }^{* \star \star} P<0.005$ (preterm vs term; Mann-Whitney $U$ test).

(term: $n=21$; preterm: $n=7$; the five missing samples involved women who had left the country).

Leptin levels followed a lognormal distribution. In interval A, pooled group levels were approximately tenfold higher in serum than in milk $(10.95 \pm 2.01$ (8.80) $\mathrm{ng} / \mathrm{ml}$ vs $1.15 \pm 0.12(1.04) \mathrm{ng} / \mathrm{ml} ; P<0.0001$, Wilcoxon signed rank test and paired $t$-test). Serum levels were higher in the term group than in the preterm group $(13.24 \pm 2.48(12.18) \mathrm{ng} / \mathrm{ml}$ vs $4.46 \pm 1.05$ (4.3) ng/ml; $P=0.03$ (the Bonferroni-corrected $P$ value was non-significant), Mann-Whitney $U$ test and unpaired $t$-test) (Fig. 1a).

Overall milk leptin levels were highest in interval A $(1.15 \pm 0.12(1.04) \mathrm{ng} / \mathrm{ml})$; they then fell to $0.79 \pm 0.10(0.56) \mathrm{ng} / \mathrm{ml}$ in interval B $(P<0.01$, Wilcoxon signed rank test) and remained at this plateau thereafter. In the term group, levels differed between intervals A $(1.34 \pm 0.14 \quad(1.35) \mathrm{ng} / \mathrm{ml})$ and B $(0.92 \pm 0.12 \quad(0.86) \mathrm{ng} / \mathrm{ml}) \quad(P<0.05$, Wilcoxon signed rank test and paired $t$-test); intervals $B$ and $C$ did not differ (Fig. 1b). In the preterm group, levels fell slightly from A to B, but did not differ significantly over the three intervals; mean levels were approximately half those of their term counterparts in intervals A $(0.63 \pm 0.18(0.31)$ vs $1.34 \pm 0.14$ (1.35) ng/ml;

Table 2 Recovery of milk samples $(n=6)$ spiked with human leptin assayed by the methods described (sonication before incubation).

\begin{tabular}{lccc}
\hline Sample & Mean \pm S.D. $(\mathrm{ng} / \mathrm{ml})$ & CV $(\%)$ & Recovery (\%) \\
\hline Unspiked & $0.34 \pm 0.02$ & 4.9 & \\
Spiked $(1 \mathrm{ng} / \mathrm{ml})$ & $1.31 \pm 0.17$ & 13.2 & 97 \\
Spiked $(5 \mathrm{ng} / \mathrm{ml})$ & $5.73 \pm 0.35$ & 6.1 & 107 \\
\hline
\end{tabular}
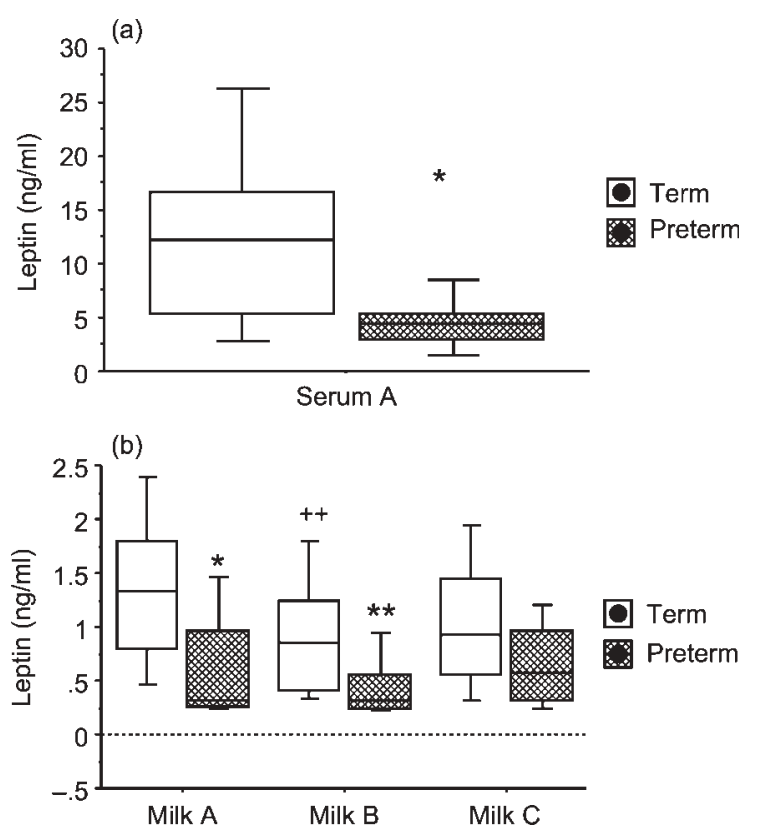

Figure 1 (a) Boxplot showing significantly lower maternal serum leptin concentration $(\mathrm{ng} / \mathrm{ml})$ after preterm $(n=6)$ than after term delivery $(n=17)$ at interval $\mathrm{A}\left(2-3\right.$ days postpartum). ${ }^{\star} P=0.03$ (Mann-Whitney $U$ test and unpaired $t$-test of log values respectively). (b) Boxplot of longitudinal milk leptin concentrations $(\mathrm{ng} / \mathrm{ml})$ after term and preterm delivery, showing significantly lower levels after preterm (A and $B: n=9, C: n=7$ ) vs term (A and B: $n=24, \mathrm{C}: n=21$ ) delivery. (A: $2-3$ days postpartum, B: 4-5 days postpartum, C: 6 weeks postpartum). A: ${ }^{\star} P<0.01$ (Mann-Whitney $U$ test), mean difference of log values $=0.37$ $\mathrm{ng} / \mathrm{ml}, P<0.005$ (unpaired $t$-test); $\mathrm{B}:{ }^{* \star} P<0.05$ (Mann-Whitney $U$ test), mean difference of log values $=0.28$ $\mathrm{ng} / \mathrm{ml}, P<0.05$ (unpaired $t$-test); the fall from A to B was significant overall $(P<0.01)$ and significant in the term group $\left({ }^{++} P<0.05\right)$, but non-significant in the preterm group (Wilcoxon signed rank test). 
$P<0.01)$ and $B(0.46 \pm 0.10(0.32)$ vs $0.92 \pm 0.12$ (0.86) ng/ml; $P<0.05)$ (Fig. 1b).

\section{Correlations}

There was a significant correlation between interval A milk and serum leptin levels $\left(\mathrm{r}^{2}=0.35(P<0.005)\right.$ by log linear regression) (Fig. 2). There was also a significant correlation between maternal serum leptin and concomitant maternal BMI (overall $\mathrm{r}^{2}=0.645$ $(P<0.0001)$ by log linear regression) (Fig. 3a). Regression was also significant for the term group but not for the preterm group. There was no significant correlation between maternal serum leptin and gestational age or birthweight.

There was a moderate correlation between maternal BMI and overall milk leptin levels in interval A $\left(r^{2}=0.15 \quad(P<0.05)\right.$ by $\log$ linear regression $)$ (Fig. 3b), but not with term or preterm levels. There was no significant correlation between maternal BMI and concomitant interval $\mathrm{C}$ leptin levels. There was moderate correlation between interval A levels and birthweight and neonatal BMI $\left(\mathrm{r}^{2}=0.16, P<0.05\right.$; data not shown).

The marked term/preterm difference in milk leptin levels in interval A was confirmed by testing the independence of this effect from maternal body weight and maternal BMI (variance analysis, ANOVA; Table 3). However, there were only small term/preterm differences considering the independence of birthweight or infant BMI $(P=0.057$ and $P=0.047)$.

\section{Discussion}

The novelty of the serial sampling practised in our study is that it provided a profile of leptin levels over three stages in human milk production: colostrum, transitional milk and mature milk, with their differing

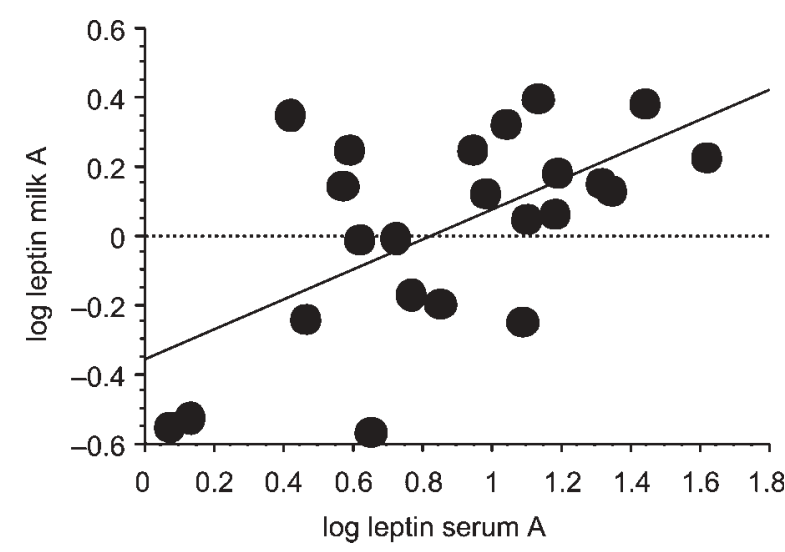

Figure 2 Correlation between leptin levels $(\mathrm{ng} / \mathrm{ml})$ in sonicated milk in interval $A$ ( $2-3$ days postpartum) $(Y)$ and corresponding maternal serum $(X)$. Log linear regression: $Y=0.43 \times X-0.36$, $r^{2}=0.35, n=23, P=0.003 ; 95 \%$ confidence. composition of fat and other ingredients, notably growth factors (11). To our knowledge, there has been no previous longitudinal study of leptin levels in human milk, whether term or preterm. We only know that, in rats, milk leptin levels fall from early to early-mid lactation, then increase again from mid to late lactation (14).

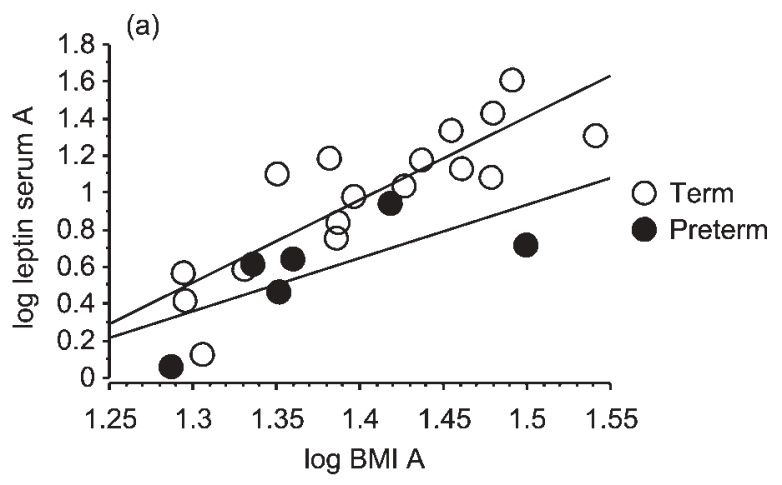

(b)

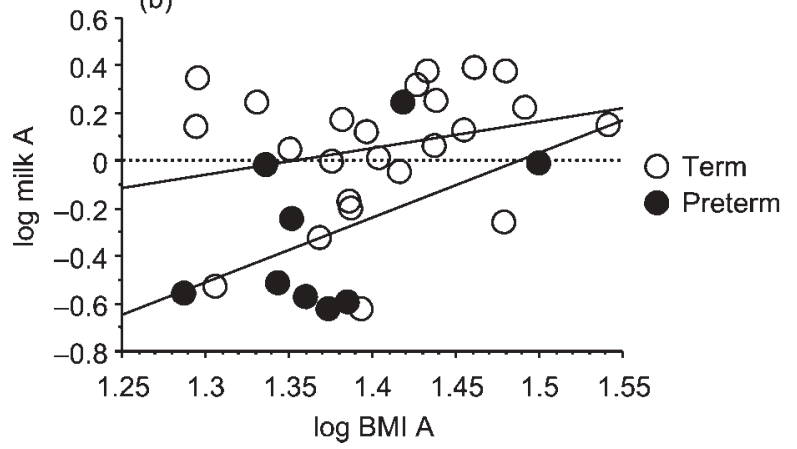

Figure 3 (a) Correlation between maternal sonicated serum leptin concentrations $(\mathrm{ng} / \mathrm{ml})(\mathrm{Y})$ and maternal BMI $\left(\mathrm{kg} / \mathrm{m}^{2}\right)(X) 2-3$ days postpartum (interval $A$ ). Log linear regressions: overall, $Y=4.40 \times X-5.27, r^{2}=0.645, n=23, P<0.0001$; term delivery, $\mathrm{Y}=4.45 \times \mathrm{X}-5.27, \mathrm{r}^{2}=0.722, n=17, P<0.0001$; preterm delivery, $\mathrm{Y}=2.87 \times \mathrm{X}-3.37, \mathrm{r}^{2}=0.522, n=6, P=0.1$; $95 \%$ confidence. (b) Correlation between sonicated milk leptin concentrations $(\mathrm{Y})$ and maternal $\mathrm{BMI}(\mathrm{X})$ in interval $\mathrm{A}(2-3$ days postpartum). Log linear regression: overall, $Y=2.04 \times X-2.89$, $\mathrm{r}^{2}=0.15, n=33, P=0.02$; term delivery, $\mathrm{Y}=1.12 \times \mathrm{X}-1.51$, $r^{2}=0.064, n=9, P=0.23$; preterm delivery, $Y=2.74 \times$ $\mathrm{X}-4.07, \mathrm{r}^{2}=0.255, n=9, P=0.17 ; 95 \%$ confidence.

Table 3 Interval A (2-3 days postpartum) milk leptin concentrations: determinants of significant preterm vs term differences.

\begin{tabular}{lc}
\hline & $\boldsymbol{P}$ value \\
\hline Preterm vs term & 0.003 \\
Preterm vs term corrected by & \\
Maternal weight & 0.004 \\
Maternal BMI & 0.008 \\
Infant weight at birth & 0.057 \\
Infant weight percentiles & 0.002 \\
Infant body mass index at birth & 0.047 \\
\hline
\end{tabular}

* ANOVA from log values. 
A limitation of our study was that since maternal blood was taken only with the colostrum sample (and omitted in ten of the 33 subjects), we had no data on the serum/milk ratio for transitional and mature milk; we were also unable, in the absence of follow-up infant weights to test for a correlation between milk leptin and infant BMI after the colostrum period. However, we recorded a number of robust findings. Leptin levels in the serum of the pooled term and preterm groups were approximately tenfold higher than in colostrum. In the term group, serum levels were approximately threefold higher than in the preterm group, and milk levels approximately double. These significant differences were unrelated to the body weight or the BMI of the mother. Neonatal weight/BMI is, however, an equivalent parameter influencing milk levels. Furthermore, leptin levels declined significantly from colostrum to transitional milk in the term group, whereas the difference remained non-significant in the preterm group, i.e. colostrum leptin levels were maintained in the transitional milk.

These features call for a physiological explanation, in particular given the general agreement between our data and those of earlier studies Our serum and milk levels were consistent with those of other workers using whole milk sonication (7), as was our finding that levels in serum or plasma exceed those in milk, with only a moderate correlation between the two $(5-7)$. In the only other study of preterm milk, Resto et al. (13) reported median absolute leptin levels approximately tenfold higher than our own $(5.28 \mathrm{ng} / \mathrm{ml}$ vs $0.63 \mathrm{ng} / \mathrm{ml})$, i.e. similar to those reported for term milk, including those in the present study. Although we have no ready explanation for this discrepancy, there remains the theoretical possibility of a term/preterm difference in that Resto et al. (13) did not incorporate term controls in their study. Their results should therefore be considered provisional in this regard.

Our finding, confirmed against internal controls, that preterm milk leptin levels were lower than their term counterparts may reflect the classic role of leptin, namely its regulatory action in metabolism and weight gain. The nature of that action, however, remains a far from coherent story. Compensatory increases in key milk components have been described in breast milk after premature delivery $(11,12,15)$. If leptin is a 'slow down' signal with respect to weight gain at an early age, then a compensatory decrease releasing the brake might be expected in preterm milk leptin levels, in the same way that exposure to high concentrations of growth-promoting factors aids catch-up development and weight gain in the premature newborn.

The fact that leptin concentrations are lower in newborns with intrauterine growth retardation than in normal neonates supports this interpretation $(P<0.001)$ (16). There is strong evidence that the fetus is leptin responsive. Fetal adipose tissue actively produces leptin as it grows, while term infants may already possess a partially functional internal leptin signalling loop. This speculation is supported by the repeated finding of a correlation between birthweight and neonatal serum leptin levels, even in the early postpartum period $(17-24)$. Considering the fact that circulating leptin levels in neonates are influenced by the kind of diet (25), premature infants are supplied with less leptin than term infants and lower circulating levels in premature than in term infants (26) can also be explained by lower leptin levels in the milk.

A lack of association between serum and milk leptin levels is likely to reflect a lack of association between maternal BMI and milk leptin levels. This is based on the assumption that a significant proportion of maternal serum leptin derives from the maternal fat mass, which closely reflects maternal BMI. Milk leptin could be transferred from maternal serum down a concentration gradient via transcytosis, as suggested by Aoki et al. (14). Given the known rise in maternal serum leptin in pregnancy and the postpartum fall (4, 27), milk leptin may at least partially be derived from the maternal circulation in the early postpartum period. Since maternal serum levels are gestation dependent, preterm milk levels will naturally start on a lower level than after term delivery. Clear in vivo evidence in rats of maternal transfer is that the injection of ${ }^{125}$ I]leptin into lactating dams is detected in the stomachs of their sucking pups and produces timedependent increases in pup blood levels (5).

However, a complicating factor is that mammary epithelial cells in vitro also directly produce and release leptin, in both rat (14) and human (8) - indeed mRNA expression in these cells approaches that found in adipocytes. In rats, milk and serum leptin levels also change quite independently of each other, making direct transfer from maternal serum an unlikely sole source (14). The contribution of mammary leptin to the patterns which we have described in this study remains unknown, as does the mechanism which might modulate mammary leptin production. Future more detailed studies in larger patient groups will seek to test the hypothesis that low leptin levels accelerate weight gain in the preterm infant, and to identify the source of milk leptin at different stages of lactation in terms of the longitudinal ratio between milk and serum (in fetus, mother and neonate) after term and preterm delivery.

\section{References}

1 Zhang Y, Proenca R, Maffei M, Barone M, Leopold L \& Friedman JM. Positional cloning of the mouse obese gene and its human homologue. Nature 1994372 425-432.

2 Schubring C, Blum WF, Kratzsch J, Deutsher J \& Kiess W. Leptin, the $o b$ gene product, in female health and disease. European Journal of Obstetrics and Gynecology and Reproductive Biology $2000 \mathbf{8 8}$ $121-127$. 
3 Highman TJ, Friedman JE, Huston LP, Wong WW \& Catalano PM. Longitudinal changes in maternal serum leptin concentrations, body composition, and resting metabolic rate in pregnancy. American Journal of Obstetrics and Gynecology $1998 \mathbf{1 7 8} 1010-1015$.

4 Mukherjea R, Castonguay TW, Douglass LW \& Moser-Veillon P. Elevated leptin concentrations in pregnancy and lactation: possible role as a modulator of substrate utilization. Life Sciences $1999651183-1193$

5 Casabiell X, Píneiro V, Tomé MA, Peinó R, Diéguez C \& Casanueva FF. Presence of leptin in colostrum and/or breast milk from lactating mothers: a potential role in the regulation of neonatal food intake. Journal of Clinical Endocrinology and Metabolism $1997 \mathbf{8 2}$ $4270-4273$.

6 Houseknecht KL, McGuire MK, Portocarrero CP, McGuire MA \& Beerman K. Leptin is present in human milk and is related to maternal plasma leptin concentration and adiposity. Biochemical and Biophysical Research Communications $1997240742-747$.

7 Ucar B, Kirel B, Boer O, Kilic FS, Dogruel N, Aydogdu SD \& Tekin N. Breast milk leptin concentrations in initial and terminal milk samples: relationships to maternal and infant plasma leptin concentrations, adiposity, serum glucose, insulin, lipid and lipoprotein levels. Journal of Pediatric Endocrinology and Metabolism $200013149-156$.

8 Smith-Kirwin SM, O'Connor DM, Johnston J, De Lancey E, Hassink SG \& Funanage VL. Leptin expression in human mammary epithelial cells and breast milk. Journal of Clinical Endocrinology and Metabolism 199883 1810-1813.

9 Uysal FK, Önal EE, Aral YZ, Adam B, Dolmen U \& Ardicolu Y. Breast milk leptin: its relationship to maternal and infant adiposity. Clinical Nutrition 200221 157-160.

10 Grosvenor CE, Picciano MF \& Baumrucker CR. Hormones and growth factors in milk. Endocrine Reviews 199314 710-728.

11 Read LC, Francis GL, Wallace JC \& Ballard FJ. Growth factor concentrations and growth-promoting activity in human milk following premature birth. Journal of Developmental Physiology 19857 $135-145$.

12 Hamosh M. Breast-feeding: unraveling the mysteries of mother's milk. Medscape Women's Health eJournal 199611 1-10 http:// www.medscape.com/viewarticle/408813.

13 Resto M, O'Connor D, Lef K, Funanage V, Spear M \& Locke R. Leptin levels in preterm human breast milk and infant formula. Pediatrics $2001 \mathbf{1 0 8}$ E15 1-4.

14 Aoki N, Kawamura M \& Matsuda T. Lactation-dependent down regulation of leptin production in mouse mammary gland. Biochimica et Biophysica Acta 19991427 298-306.

15 Luukkainen P, Salo MK \& Nikkari T. Changes in the fatty acid composition of preterm and term human milk from 1 week to 6 months of lactation. Journal of Pediatric Gastroenterology and Nutrition 199418 355-360.

16 Jaquet D, Leger J, Levy-Marchal C, Oury JF \& Czernichow P. Ontogeny of leptin in human fetuses and newborns: effect of intrauterine growth retardation on serum leptin concentrations. Journal of Clinical Endocrinology and Metabolism $1998 \mathbf{8 3}$ $1243-1246$.

17 Koistinen HA, Koivisto VA, Andersson S, Karonen SL, Kontula K, Oksanen L \& Teramo KA. Leptin concentration in cord blood correlates with intrauterine growth. Journal of Clinical Endocrinology and Metabolism $1997 \mathbf{8 2} 3328-3330$.

18 Matsuda J, Yokota I, Iida M, Murakami T, Naito E, Ito M, Shima K \& Kuroda Y. Serum leptin concentration in cord blood: relationship to birthweight and gender. Journal of Clinical Endocrinology and Metabolism $1997 \mathbf{8 2} 1642-1644$.

19 Schubring C, Kiess W, Englaro P, Rascher W, Dötsch J, Hanitsch S, Attanasio A \& Blum WF. Levels of leptin in maternal serum, amniotic fluid, and arterial and venous cord blood: relation to neonatal and placental weight. Journal of Clinical Endocrinology and Metabolism 199782 1480-1483.

20 Tamura T, Goldenberg RL, Johnston KE \& Cliver SP. Serum leptin concentrations during pregnancy and their relationship to fetal growth. Obstetrics and Gynecology 199891 389-395.

21 Geary M, Herschkovitz R, Pringle PJ, Rodeck CH \& Hindmarsh PC. Ontogeny of serum leptin concentrations in the human. Clinical Endocrinology 199951 189-192.

22 Geary M, Pringle PJ, Persaud M, Wilshin J, Hindmarsh PC, Rodeck CH \& Brook CG. Leptin concentrations in maternal serum and cord blood: relationship to maternal anthropometry and fetal growth. British Journal of Obstetrics and Gynaecology $19991061054-1060$.

23 Schubring C, Siebler T, Kratzsch J, Englaro P, Blum W, Triep K \& Keiss W. Leptin serum concentrations in healthy neonates within the first week of life: relation to insulin and growth hormone levels, skinfold thickness, body mass index and weight. Clinical Endocrinology 199951 199-204.

24 Wiznitzer A, Furman B, Zuili I, Shany S, Reece A \& Mazor M. Cord leptin level and fetal macrosomia. Obstetrics and Gynecology 2000 $96707-713$.

25 Savino F, Costamagna M, Prino A, Oggero R \& Silvestro L. Leptin levels in breast-fed and formula-fed infants. Acta Paediatrica 2002 $91897-902$.

26 Spear ML, Hassink SG, Leef K, O'Connor DM, Kirwin SM, Locke R, Gorman R \& Funanage VL. Immaturity or starvation? Longitudinal study of leptin levels in premature infants. Biology of the Neonate $2001 \mathbf{8 0} 35-40$.

27 Butte NF, Hopkinson JM \& Nicolson MA. Leptin in human reproduction: serum leptin levels in pregnant and lactating women. Journal of Clinical Endocrinology and Metabolism $1997 \mathbf{8 2}$ 585-589.

Received 15 December 2003

Accepted 5 May 2004 